\title{
Rethinking US climate advocacy
}

\author{
Amy Luers
}

Received: 20 November 2012 / Accepted: 18 May 2013 /Published online: 6 June 2013

(C) The Author(s) 2013. This article is published with open access at Springerlink.com

\begin{abstract}
The US climate movement has failed to create the political support needed to pass significant climate policy. It is time to reassess climate advocacy. To develop a strategy for philanthropy to strengthen climate engagement, I interviewed over 40 climate advocates,more than a dozen representatives from the foundation community, and a dozen academics. My assessment led me to conclude that climate advocates have focused too narrowly on specific policy goals and insufficiently on influencing the larger political landscape. I suggest four ways to improve climate advocacy: 1) Increase focus on medium and longer-term goals; 2) Start with people and not carbon; 3) Focus more on values and less on science; and 4) Evaluate what works and share what we learn. To accomplish these strategies, social scientists and advocates must work together to build a culture of learning. Meanwhile, philanthropy must empower experimentation and incentivize knowledge sharing.
\end{abstract}

Decarbonizing the US economy is primarily a social and political challenge. We already have the technical know-how to achieve significant carbon reductions, yet social inertia and vested corporate and political interests are preventing progress. To reduce the extent and severity of future climate change, we must break through these barriers and build greater demand and political will for significant climate policy.

Today, most Americans believe that climate change is real and at least partly human caused (Leiserowitz et al. 2012; Boston Krosnick et al. 2009). However, after over a decade of extensive efforts by advocates and scientists to engage the public on the issue, the vast majority of Americans still see climate change as a low priority issue (Pew 2012; Nisbet and Myers 2007). Until it rises higher in society's concerns, we will only nibble around the edge of addressing this crisis. To shift this trend, many in the community have begun to rethink their approach to climate advocacy.

One key reason we have failed to pass comprehensive climate legislation, recent studies argue, is that advocates have not effectively engaged the public, especially at the grassroots level (Bartosiewicz and Miley 2013; Skocpol 2013). This shortcoming can be attributed in part to how the philanthropic sector has prioritized its funding, focusing largely on policy and technical approaches to environmental issues, rather than the social and political dimensions of

A. Luers $(\bowtie)$

Skoll Global Threats Fund, San Francisco, CA 94129, USA

e-mail: aluers@skollglobalthreats.org 
addressing environmental problems (Brulle and Jenkins 2005). While lack of effective public engagement is not the only reason for the failure of climate legislation, it is clear that a broader consideration of the social and political challenges to solving the climate crisis is needed.

This discussion needs to involve more than just advocates and funders. It must also include social and climate scientists working at the interface of science, policy, and action. The engagement of social scientists is critical for linking research to action, the engagement of climate scientists is also critical as they will continue to be messengers of the evolving climate crisis. As a scientist who has led climate advocacy campaigns and now directs a climate funding program, I seek to integrate these sometimes divergent vantage points and help focus the discussion on a productive path forward.

Over the last year, I examined the challenge of climate engagement through the lens of philanthropy, exploring how we could better empower the advocacy community to take a new approach. With the help of several colleagues and consultants, I interviewed over 40 climate advocates, more than a dozen representatives from the foundation community, and about a dozen leading social scientists working on these issues (more on this research can be found in Luers 2013). Four major themes emerged from this research about how climate advocacy could be more effective: (1) taking a longer-term view, (2) starting with people, (3) focusing on values, and (4) evaluating and sharing what works. Below I detail the rationale for each of these, identify barriers to implementing them, and suggest actions to overcome those barriers.

\section{Increase focus on medium and longer-term goals}

The sense of urgency of the climate crisis has pressed the climate movement to focus too narrowly on the battle of the moment, rather than focusing on the larger war. Over the last decade, many millions of dollars have been poured into outreach and advocacy efforts (Skocpol 2013; Bartosiewicz and Miley 2013). While we have had our share of policy successes, we have failed to build the political will needed for significant national climate policy. As the fight for the national healthcare legislation made apparent, even when a bill is passed, if the political support for that bill is not strong, it can be an uphill battle to implement the policy. This suggests the need to look beyond individual policy fights to a broader focus on shifting the political landscape.

In ecology, we would refer to this perspective as managing for "slow changing" rather than "fast changing" variables. For years, managers of lake systems focused on managing the water clarity of lakes (a fast changing variable), which can change quickly after a storm or heavy use by people. However, eventually, ecologists recognized the need to focus more on soil erosion and nutrient levels, which ultimately control the vulnerability of a lake to algae blooms and decreasing water clarity (Janssen and Carpenter 1999; Carpenter and Cottingham 1997). Ecology tells us that if we focus on the slow changing variables, managing fast changing variables will be easier.

The climate movement has been hyper focused on fast changing variables, such as public opinion, which fluctuates with the weather (Krosnick et al. 2006) and the economy (Krosnick and MacInnis 2012) and on winning the policy opportunity of the moment (e.g. cap and trade, renewal portfolio standards or carbon tax), protecting regulations under threat (e.g. EPA) or attacking new proposals (e.g. Keystone, coal power plants). These have all been important battles, but have largely not been approached with the longer-term political needs in mind, and as a result they have failed to build the political will needed to pass policies to cut greenhouse gas emissions to levels needed to avoid the most severe impacts of 
climate change. We need to start picking our battles, designing our campaigns, and assessing our losses and wins with this endgame in mind.

As any good chess player knows, while you need to eliminate some of your opponent's pieces to weaken her position, you do not need to get all of her pieces to win the game; you only need the king. If you lose sight of this, you will fight unnecessary battles, fail to recognize when to make sacrifices, and not know what to do when no clear battle is in sight.

\section{Start with people and not carbon ${ }^{1}$}

Most climate advocacy efforts start with carbon, asking: How many tons of carbon (emitted) do we need to reduce? Where can we get those reductions? And what is the next policy opportunity to make that happen? (e.g. Pacala and Socolow 2004; CEA 2007). This approach has enabled us to achieve important victories such as renewable energy standards, fuel economy standards, and coal plant closures. However, these were relatively low hanging fruit, and we remain far from the comprehensive change we need.

Enacting policies to transition the US to a low carbon economy requires taking a "people first" approach. Such an approach would start with questions such as: How strong a political and public base of support do we need to enact significant national climate policies? Where can we get this base of support? And how can we build it?

After years of research, and philanthropic investment, we know the answers to the carbon-based scientific and policy questions. However, we have only begun to ask the questions about building the strong political base needed to enact these policies. Most advocates have very limited knowledge about how to effectively engage people on complicated issues such as climate change. As Frances Beinecke, the President of the Natural Resources Defense Council, explained: "We have a lot of polling - most of it either leaning towards a conclusion or designed to sell a specific strategy. But understanding how to engage the public requires a bigger body of knowledge..." Parts of this larger body of knowledge exist, but finding them requires looking beyond polls. As Suzanne Shaw, the Communication Director for the Union of Concerned Scientists, told me " polls provide a snapshot of 'where the public is' but tell us less about how we move key segment of the population from point A to point B." Advocacy efforts need to begin to focus on understanding and targeting campaigns around those factors that drive key populations to move from "point A to point B."

Furthermore, we need to begin to track our progress toward these goals. Today, the only long-term data to help track indicators of political will are surveys of public attitudes, which are all at a national scale and cover only broad issues (Pew 2012; Leiserowitz et al. 2012; Gallup 2012). While these are interesting, they are of limited value for tracking our progress because they provide no information about influencing attitudes in the key sectors of the population that need to be engaged. For example, according to Gallup, there has apparently been little change in US public opinion on climate over the last two decades (Gallup 2012). However, national average data could mask important changes, such as a rise in concern California and a decline in Florida and Ohio. As a result, while we know quite precisely how we are doing on carbon reductions, we have little knowledge about how effectively we are moving the relevant populations across the nation.

\footnotetext{
${ }^{1}$ Thank you in particular to Eric Heitz of the Energy Foundation for key insights that helped frame this section.
} 


\section{Focus more on values and less on science}

Many climate engagement efforts are driven by the outdated "information deficit" theory of science communication. The "deficit model" refers to the idea that public uncertainty and skepticism around climate change is caused primarily by a lack of understanding of the science (Moser and Dilling 2011; Maibach et al. 2008; O'Brien 2012). If this were correct, the obvious solution would be to increase public understanding of climate science.

However, social science research suggests that a person's scientific literacy has little relationship with their level of concern over climate change (Kahan et al. 2012). Most people's beliefs are formed largely by their values, community and culture (Kahan and Braman 2005). This research suggests that advocates for climate policy should focus less on increasing the public's understanding of climate science, and more on building the culture and values that support action. As the congressman Ed Markey, a proponent of climate legislation and the US Representative for Massachusetts's 5th congressional district, argued, "We need to win back the science, but we will - that's the easy part. The more difficult question is whether we win back the principle that if the science is valid, public policy action is morally mandatory..." This is the crux of the problem. I heard the same point from a voice on the other side of the political spectrum, Eli Lehrer, a former Heartland Institute employee and the president of $\mathrm{R}$ Street, a conservative think tank: “... being right about science DOES NOT by itself make somebody's proposed public policy solutions infallible." It is clear that without a moral mandate, science isn't enough.

The conservative movement figured this out 40 years ago, starting with the future Supreme Court Justice Lewis Powell's famous memo for the US Chamber of Commerce in 1971. The Powell Memo called for a long-term strategy to shape and strengthen conservative values by establishing a web of think tanks, research institutions, and media networks to promote basic principles such as free markets, self-reliance, and limited regulation. Forty years of simple messages, repeated often by trusted leaders, slowly but effectively created a cultural identity that anchored many conservative ideas in popular beliefs (Meagher 2012), including a link between anti-regulation values and antienvironmentalism (McCright and Dunlap 2010). Although climate change was a latecomer to the list of environmental issues, it fit neatly into existing storylines. In fact, the fear that climate policy could include economy-wide regulation brought the issue to the center of the culture wars (Hoffman 2012).

To take control of the conversation we need to shift the focus of climate engagement efforts. Instead of asking what the public needs to know about climate science, we should ask what the values are that support climate action. Social marketing groups, like ecoAmerica, have begun to take a values-based approach for engaging the public on climate primarily by selling it as a personally relevant issue. Many other advocates are taking a similar approach, arguing as Eric Pooley, Sr. Vice President at Environmental Defense Fund does that "as this abstract problem becomes real, public support for action rises." While the evidence suggests that linking the local threats of extreme weather, such as droughts, floods, and hurricanes, to climate change has successfully put the issue in the public discourse, it has so far not lead to building the political support needed for significant climate action. Meanwhile, the conservative movement's long-term effort to shape a culture has set the terms of the discourse around pending climate catastrophe. The prevailing narrative is that the dire warnings of climate scientists and advocates are just scare tactics to enable big government to impose more regulation (Klein 2008).

To move past this narrative, we need to take the values-based approach beyond social marketing, that can lead to spin wars, to democratic engagement to build new norms (Brulle 
2010). As Daniel Kahneman, Nobel Prize winning behavioral economist, explained to me “ the motivating force for protective action is either a routine norm (e.g. purchasing fire insurance) or the emotional arousal of fear of dread. The threat of global warming is too abstract and remote to evoke dread and fear." If we don't have fear and dread, Kahneman suggests our only hope is to define the norm. We need to identify and elevate those values that can define a new norm focused on building a culture where actions to protect current and future generations from climate risks becomes routine. For example, research suggests that egalitarian, communitarian worldviews, whereby people value their commitment to fairness and to each other, correlate strongly with concern over climate change, and support for action to protect future generations (Leiserowitz 2006).

\section{Evaluate what is working and share what we learn}

Knowing what works is critical for an effective campaign. Yet the climate movement does not have a systematic approach to evaluate and learn from ongoing campaign efforts. Advocates have designed policy solutions and tested messages on how to market these to specific audiences. We have researched and re-researched whether to frame the climate crisis as "global warming," "climate change," or "climate chaos." Meanwhile, we continue to base our actions on educated hunches such as elevating the "extreme weather message" or "engaging the faith community" with little evidence about how these campaigns might support or conflict with each other in shifting the political landscape toward support of climate action. Social scientists working in this area encourage the community to be more systematic in its approach to climate engagement. Dan Kahan, a professor with the Cultural Cognition Project at Yale University, said, "Don't guess about what to do; treat insights as hypotheses then observe, measure, and report the actual effect of strategies you use. ' Similarly, Baruch Fischhoff, a professor of social and decision sciences at Carnegie Mellon University, encouraged advocates to "evaluate communications to a scientific standard, in order to improve their design and learn from experience." Although some campaigns have integrated experimentation and effectiveness assessments, such as the Clean Air Defense effort to defend the EPA's authority to regulate $\mathrm{CO} 2$, these efforts are still in their infancy.

Over the last 5 years, political research techniques and analyses have grown in sophistication, enabling analysts to learn a good deal about what works and what does not in political campaigns. Much of the experimentation and testing that takes place in the progressive political community is linked to the Analyst Institute, an applied research center that integrates experimental design into political campaigns and has developed a clearinghouse of evidence-based best practices for contacting voters. The Analyst Institute has been enabled by data collection and aggregation centers such as Catalist (a voter database) and the Polling Consortium (a shared database of electoral polling). The vast amounts of data and knowledge accumulated by these efforts have helped partner organizations generate a greater impact for each campaign dollar spent, and, at the same time, helped identify best practices. Bringing this experimental, data-driven approach to climate advocacy could expand reach and increase impact.

\section{The way forward}

Here I have suggested four strategies to enhance the effectiveness of climate advocacy. To implement these strategies, funders must make it easier for advocacy organizations to set 
longer-term goals, empower experimentation and incentivize sharing. Advocates, in turn, must focus more on people and less on carbon, and move beyond improving scientific literacy to inspiring action based on our shared core values. Finally, social scientists, advocates, and philanthropists must work together to develop a culture of learning so that we can prioritize the methods of public engagement that are most effective.

The proposals presented here are not quick fixes to the climate crisis. Unfortunately, there are no quick fixes. Social change takes time, as does implementing technological change. We must accept and plan for the reality of the pace of change that we face. This requires developing a strategy for building political will over the medium and long-term, while continuing to pursue short-term policy wins. I offer the four themes outlined above as a framework for building that strategy as we rethink our approach to public engagement on climate change

Acknowledgments I would like to thank the members of the climate community who shared their thoughts and insights during my research. Thanks also go to Carl Pope and David Kroodsma for their assistance with research. Bruce Lowry and Leonard Sklar provided helpful reviews of the text. Finally, many thanks go to three anonymous reviewers for their helpful comments and suggestions.

Open Access This article is distributed under the terms of the Creative Commons Attribution License which permits any use, distribution, and reproduction in any medium, provided the original author(s) and the source are credited.

\section{References}

Bartosiewicz P, Miley M (2013) The too polite revolution: why the recent campaign to pass comprehensive climate legislation in the United States failed. Columbia journalism school centennial report. Prepared for the symposium on the politics of America's fight against global warming

Brulle RJ (2010) From environmental campaigns to advancing the public dialog: environmental communication for civic engagement. Environ Commun J Nat Cult 4(1):82-98

Brulle R, Jenkins JC (2005) Foundations and the environmental movement: Priorities, strategies, and impact. In: Faber D, McCarthy D (eds) Foundations for social change: Critical perspectives on philanthropy and popular movements. Rowman \& Littlefield, New York, pp 151-173

California Environmental Associates (CEA) (2007) Design to Win. at http://www.climateactionproject.com/ docs/Design_to_Win_8_01_07.pdf Accessed 19 November 2012

Carpenter S, Cottingham $\bar{K}$ (1997) Conservation ecology: resilience and restoration of lakes. Ecol Soc 1:2

Gallup (2012) Americans' worries about global warming up slightly. at http://www.gallup.com/poll/153653/ Americans-Worries-Global-Warming-Slightly.aspx Accessed 19 November 2012

Hoffman AJ (2012) Climate science as culture war. Stanford social innovation review. Fall issue pp 31-37

Janssen M, Carpenter S (1999) Conservation ecology: managing the resilience of lakes: a multi-agent modeling approach. Ecol Soc 3:15

Kahan DM, Braman D (2005) Cultural cognition and public policy. Yale Law Policy Rev 24:147-170

Kahan DM, Peters E, Wittlin M et al (2012) The polarizing impact of science literacy and numeracy on perceived climate change risks. Nat Clim Chang 2:732-735. doi:10.1038/nclimate1547

Klein N (2008) The shock doctrine: The rise of disaster capitalism. Picador

Krosnick J, MacInnis B (2012) Trends in american public opinion on global warming policies between 2010 and 2012. at http://woodsinstitute.stanford.edu/sites/default/files/files/GW-Policy-Trend-2010-2012-1.pdf Accessed April, 10, 2012

Krosnick J, Holybrook AL, Lowe L, Visser PS (2006) The orgins and consequences of democratic citizen's policy agendas: a study of popular concern about global warming. Clim Chang 77:7-43. doi:10.1007/ s10584-006-9068-8

Krosnick JA, Malka A, Yeager DS (2009) State of the nation: getting warmer. Boston Rev 34:6

Leiserowitz A (2006) Climate change risk perception and policy preferences: the role of affect, imagery, and values. Clim Chang 77:45-72. doi:10.1007/s10584-006-9059-9 
Leiserowitz A, Maibach E, Roser-Renouf C, Hmielowski J (2012) Global warming's six Americas in March 2012 and November 2011. Yale project on climate change communication. at http:// environment.yale.edu/climate/files/Six-Americas-March-2012.pdf Accessed 20 November 2012

Luers A (2013) Taking stock: U.S. climate engagement, Skoll Global Threats Fund discussion piece. http:// www.skollglobalthreats.org/wp-content/uploads/2013/03/TakingStock-FINAL.pdf

Maibach EW, Roser-Renouf C, Leiserowitz A (2008) Communication and marketing as climate changeintervention assets. Am J Prev Med 35:488-500. doi:10.1016/j.amepre.2008.08.016

McCright AM, Dunlap RE (2010) Anti-reflexivity: the American conservative movement's success in undermining climate science and policy. Theory Cult Soc 27:100-133. doi:10.1177/0263276409356001

Meagher R (2012) The "Vast Right-Wing Conspiracy": media and conservative networks. New Polit Sci 34:469-484

Moser S, Dilling L (2011) Communicating climate change: Closing the science-action gap. In: Dryzek JS, Norgaard RB, Schlosberg D (eds) The Oxford handbook of climate change and society. Oxford University Press, USA, pp 161-174

Nisbet MC, Myers T (2007) The polls - trends twenty years of public opinion about global warming. Public Opin Q 71:444-470. doi:10.1093/poq/nfm031

O'Brien K (2012) Global environment change III: closing the gap between knowledge and action. Prog Hum Geogr. doi:10.1177/0309132512469589

Pacala S, Socolow R (2004) Stabilization wedges: solving the climate problem for the next 50 years with current technologies. Science 305:968-972. doi:10.1126/science.1100103

Pew (2012) Green car congress: Pew survey finds US public ranks economy as highest priority policy issue, global warming as lowest. at http://www.greencarcongress.com/2012/01/pew-20120124.html Accessed 19 November 2012

Skocpol T (2013) Naming the problem: What it will take to counter extremism and engage Americans in the fight against global warming. Harvard University. Prepared for the symposium on the politics of America's fight against global warming 